\title{
MODELLING OF VTS SUPERVISOR BY ALGORITHM BASED ON PETRI NET: CASE STUDY OF DOVER INCIDENT
}

\author{
Rino BOŠNJAK ${ }^{*}$, Danko KEZIĆ ${ }^{1}$, Goran BELAMARIĆ1 ${ }^{1}$, Srećko KRILE ${ }^{2}$ \\ ${ }^{1}$ Faculty of Maritime Studies, University of Split, Croatia \\ ${ }^{2}$ Dept of Electrical Engineering and Computing, University of Dubrovnik, Croatia
}

Submitted 19 February 2020; resubmitted 20 July 2020, 1 February 2021; accepted 2 April 2021

\begin{abstract}
The paper deals with collision prevention problem in maritime transport in the area of the narrow canals with predefined routes. The Dover incident, which is analysed and described in the paper, has shown that the control of the passage of ships through the critical areas must be upgraded with an automatic supervising system, which warns the human operator of incorrect ship motion and help the operator to make the right and timely decision. The general idea is to improve the safety of navigation by introduction of automatic collision prevention based on automated supervisor helping to human operator in Vessel Traffic System (VTS) control centre. The VTS supervisor automatically monitors marine traffic by using data from Automatic Radar Plotting Aid (ARPA) radar and others sensors. Such supervisor detects real time and Course Over Ground (COG) of the vessel entering a particular sector, and then estimates the required time for vessel's passage into another sector. VTS supervisor compares the real time and estimated time of passage of the specific ship through particular sector as a part of surveillance area. In addition, it compares and monitors the deviation of the course during transition of zones (sectors). If significant difference for both values are occurred VTS supervisor triggers a time alarm or a course alarm respectively. In the paper authors have modelled and simulated collision prevention with performed by the alarm actions of VTS supervisor improved with algorithm module based on hybrid Petri net formalism and Visual Object Net ++ tool.
\end{abstract}

Keywords: discrete event systems in maritime, Dover incident, hybrid Petri net, maritime sector supervisor, maritime traffic control centre, maritime collision prevention, Visual Object Net ++ .

\section{Notations}

$$
\begin{aligned}
& \text { Variables and functions: } \\
& \begin{array}{l}
m_{0} \text { - initial marking; } \\
P \text { - set of places; } \\
R \text { - route; } \\
T \text { - set of transitions; } \\
w \text { - weight function; } \\
Z \text { - discrete places. }
\end{array}
\end{aligned}
$$

CZT - crossing zone time;

ECDIS - electronic chart display information system;

HPR - call sign of the observed vessel;

INS - information service;

LNG - liquefied natural gas;

MAIB - marine accident investigation branch;

MSA - maritime situational awareness;

NAS - navigational assistance service;

NNE - north northeast;

SOG - speed over ground;

SSW - south southwest;

TOS - traffic organisation system;

TSS - traffic separation schemes;

$\mathrm{V} / \mathrm{L}$ - vessel;

VTS - vessel traffic system.

*Corresponding author. E-mail: rbosnjak@pfst.hr 


\section{Introduction}

The factors, which affect the safety of the vessel, the people, the environment and the property include the grounding, collision, fire, capsizing, failure of the main power supply, damage to the main hull, pollution and so on. To avoid potential collision in a dense traffic area, it is necessary to enhance the existing VTS particularly in the Dover Strait. The CNIS helps vessels to navigate safely and prevent collision in the Dover Strait (MCGA 2014; Bielić et al. 2017; Neill 1990). The CNIS provides 24 -hour radio and radar service for all shipping in the Dover Strait. The Dover Strait is a mandatory reporting area, which means that vessels over 300 gross tones sailing to Dover (South West Lane) or to Gris Nez (North East Lane) have to report their passage before proceeding through the service area. Therefore, it is recommended to enhance some parameters concerning the safe passage of vessels. In addition, for further research on Dover Strait navigation, it is important to note that traffic has increased by $71 \%$ since 1971 (Cockcroft 2004). The main function of the CNIS is to keep the Dover Strait TSS under observation, to monitor the flow of traffic, to detect and report the vessels contravening the International Regulations for Preventing Collisions at Sea 1972 (COLREGs, as amended) (Emden 1983).

The supervision of maritime traffic is carried out by the VTS operator from the land-based VTS centre. The VTS information system collects, integrates, analyses and presents data from various sensors, and uses a wide range of hardware and software modules (Kim 2013; Weng et al. 2012). The states of the vessels during navigation are presented to VTS operators in an acceptable way, regardless of whether the end users are ashore, in big or small ports, on board ship, river or offshore platform.

The principal problem is the large number of data from ships that the VTS operator must process in real time. Therefore, in order to help the human operator, all data given by the VTS to the operator must be divided in levels (Chong 2018). These levels correspond to the organization, enhancing of safety of life and properties, and environment protection. The levels contribute to reducing the risk of marine operations, enhancing the efficient navigation and performance of port resources (Porathe et al. 2014; Praetorius 2014). The distribution of all information is essential within the VTS, assistance during search and rescue operations and data logging for further analysing and administration purpose.

This paper discusses different approaches to automatic real time monitoring. There is a method of processing AIS data by linear filtering using ARMA models (Patmanidis et al. 2016) where the author shows the possibility of monitoring traffic in real time and reporting abnormalities in vessels' behaviour. In that paper, the author proposes two ways of detecting anomalies. In the first method, the lack of AIS data can trigger a signal alert (there is no defined time period for lack of data), while the other method defines the maximum speed for a particular type of ship: if the vessel's speed is higher than the feasible velocity, an alert signal is given (there is no range between these speeds indicating when the alert should be triggered). Another method, using historical AIS data to improve MSA, is developed for quality of vessel prediction (Mazzarella et al. 2015). Another research method using safety factors assign to vessel, which entering particular sector and amount of vessels has to be controlled by sector load (Filipowicz 2004). The sector load should not exceed its capacity and safety factor as per type of craft is defined. But with type of craft is reduced transit in narrow area and applying this method would restrict transit as per various types of crafts, which would lead additionally reducing of flow in narrow areas. All methods increase the safety of navigation in narrow straits but none of them gives an example of a supervisor that can be integrated in the VTS system for an early warning of VTS operators.

Another research by Lee et al. (2010) was conducted in Korean waters where they were testing marine traffic supporting system based on a model that calculates stress when a vessel is in the vicinity of land or ship. Taking these two stresses into consideration, the model calculates general stress, which will be shown in the electronic chart in the VTS system. Based on the calculated stress, the VTS operator should make the final decision in close quarter situations. Eventually, the ship's master has to decide whether to follow the VTS operator's final decision, but with the proposed methodology, the master will be advised well advance about the situation.

Additional research method was used in Istanbul Strait to improve local traffic management, which would improve marine traffic safety (Aydogdu et al. 2012). This method used environmental stress and can numerically identify current safety level, which can be used as additionally support in research studies given in this paper.

Furthermore, there is a paper by Bošnjak et al. (2020), whose authors propose the synthesis of an early warning "crossing supervisor", which controls the number of vessels simultaneously passing through the crossings, taking into account the priority of the vessel entering the sector and the degree of importance of the vessel. The maximum number of vessels in the period of time of the highest traffic density through the crossings are determined. The set of constraints for crossings is defined, and then the supervisor is calculated by using Petri nets with discrete places and transitions and the P-invariant method.

The main idea of this study is to obtain the synthesis of an early warning "sector supervisor that monitors marine traffic by using data from ARPA in the VTS centre". The supervisor detects each ship's COG and the time of entry into the sector for each ship, and then estimates the required time for the vessel's moving into another sector. When the ship leaves the sector, the supervisor compares the exit time and the estimated time and, if a significant difference occurs, triggers a time alarm. The model for the supervisor in this study uses hybrid Petri nets consisting of discrete and continuous places and transitions. 
The paper is organised as follows: the introduction shortly presents the problem of the safety in maritime transport. Section 1 describes the Dover Strait and the incident that occurred. Section 2 describes the basics of the VTS supervisor, the basic terms used in this paper and the main tasks of the proposed collision prevention supervisor. Section 3 describes modelling of the collision prevention supervisor by using Petri nets. Here the general and hybrid Petri nets are explained. Section 4 provides a description of the simulation by using hybrid Petri nets. Section 5 presents the results and discussion. Finally, the concluding remarks including references are given.

\section{Dover incident: description and analysis of the incident}

The number of inter-ship collisions and hazardous incidents within the TSS, recorded by Dover Coastguard or Cross de Gris Nez or reported to the MAIB give cause for some concern. The severity of these incidents - to use a motoring analogy - ranges from the relatively minor offence of "driving without due care and attention" through to the more serious "dangerous driving where loss of life has occurred". Every one signifies a breach of one or other of the COLREGs (Squire 2003):

"» $48 \%$ were crossing situations;

"» $26 \%$ were overtaking;

"» $26 \%$ involved a fishing or rogue vessel.

Here is a brief description of the incident involving an LNG tanker on route from the Isle of Grain to the Suez Canal in ballast condition. The bridge team consists of the master, 2nd officer, helmsman and watch keeping rating. The vessel, which caused the incident (deviation in turning off course and into the opposite direction in the one-way TSS) reassessed the situation and aborted the overtaking manoeuvre, due to various contributing factors such as:

"»" proximity to navigation hazard (south fall buoy and the surrounding area - shallow water);

"I) uncertainty of the vessel ahead of her on the port side;

"»" prediction that the observed vessel and the vessel ahead on the port side (named with call sign in Figures 1 and in Figure 2 as HPR) will arrive at south fall buoy at the same time.

Due to the above-mentioned factors, the vessel started her manoeuvre over starboard side as in Figure 1 (where the observed vessel is named as Group V/L).

After several minutes, the vessel in Figure 1 (Group $\mathrm{V} / \mathrm{L}$ ) altered more than $180^{\circ}$ going to the opposite course, which could lead to near collision situation with another vessel, as in Figure 2.

Figures 1 and 2 have shown how to develop and introduce the supervisor in VTS, whose implementation would improve the safety of passage in straits such as Dover and decrease the probability of incidents that are likely to result in major marine accidents.

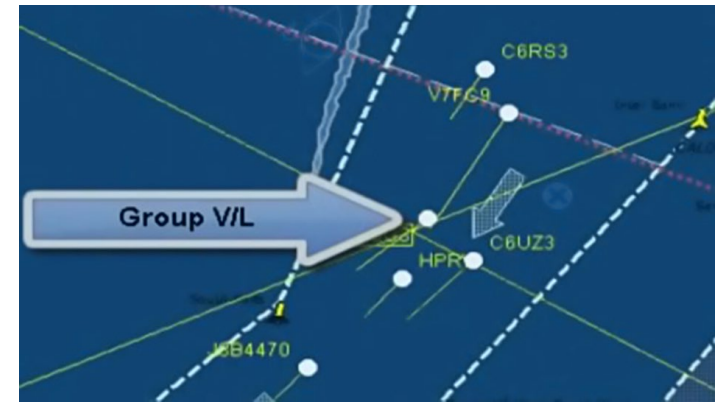

Figure 1. Observed vessel before starting turning to starboard (compiled by authors)

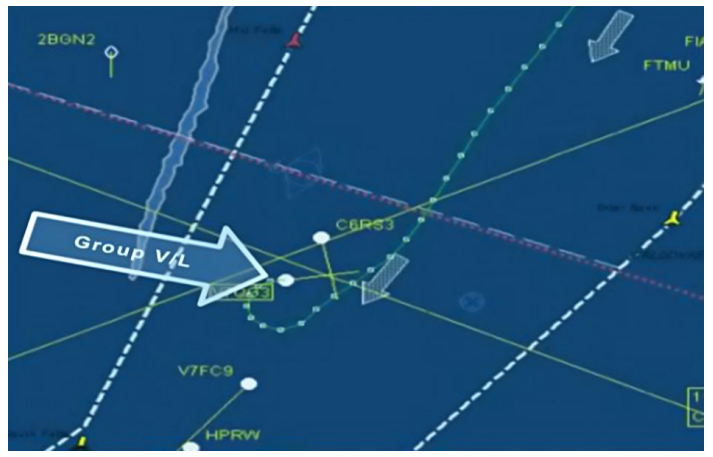

Figure 2. Observed vessel after turning to the opposite course (compiled by authors)

\section{VTS supervisor}

As it can be seen in a Dover Strait incident example, ship captains can navigate their vessels in a prohibited direction and in an unpredictable way. If that happens in the areas of high traffic density, the VTS operators are often unable to detect the unpredictable behaviour of certain vessels in time using only VTS system, and that can often jeopardize the safety of navigation and endanger other vessels in close vicinity. For this reason, the authors propose the way to automate the detection of ships carrying out unauthorized manoeuvres and alert the VTS operator in time. This can be done by using a VTS supervisor that is added to the VTS system.

As presented in Figure 3, the authors suggest that the area of dense traffic in the Dover Strait should be divided into zones of length and width size of $0.5 \mathrm{~nm}$. The size of a sector can be adjustable, depending on the traffic flow in the separation scheme.

The separation scheme runs from NNE to SSW and back in the opposite direction. The shading in Figure 3 represents the area of interest where the near miss incident occurred. The red shading area is the monitored area, divided into five sectors, where turning of the LNG ship occurred. Figure 4 shows a block scheme of a VTS system with an embedded VTS supervisor proposed in the paper. The standard VTS system consists of various devices, of which the crucial ones are:

»» ECDIS;

"m) ARPA;

"» AIS. 


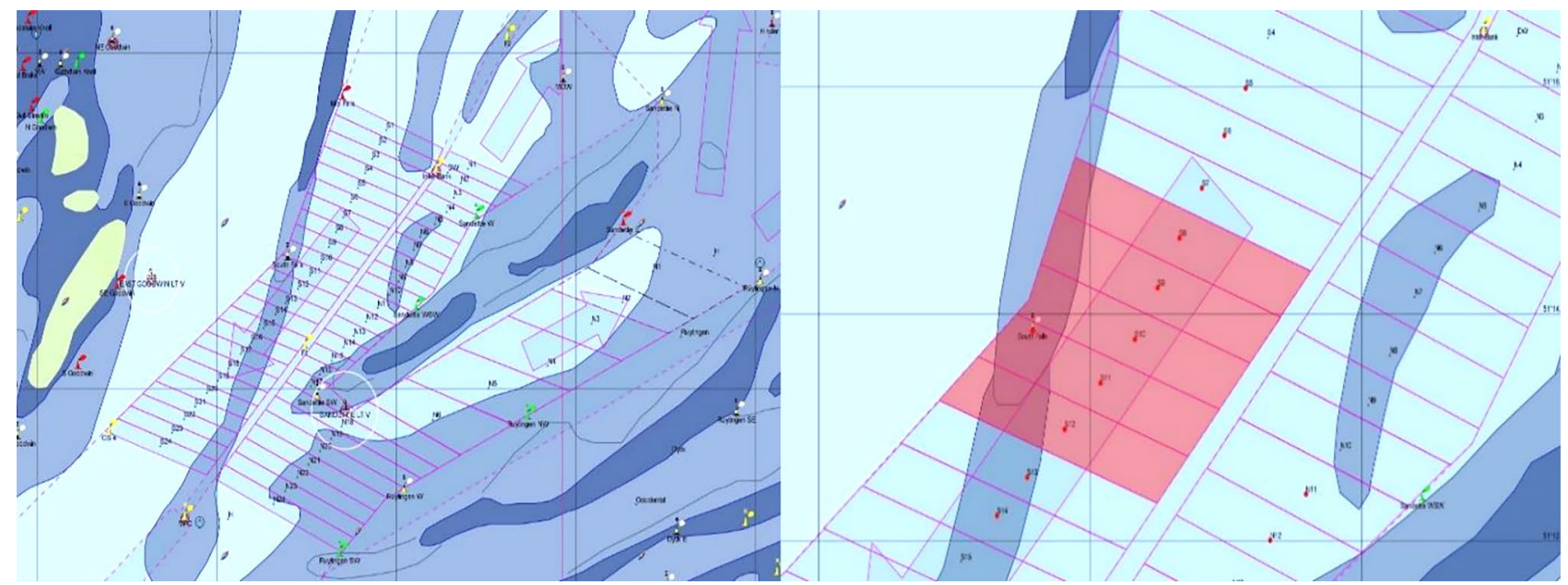

Figure 3. Dover Strait divided into zones

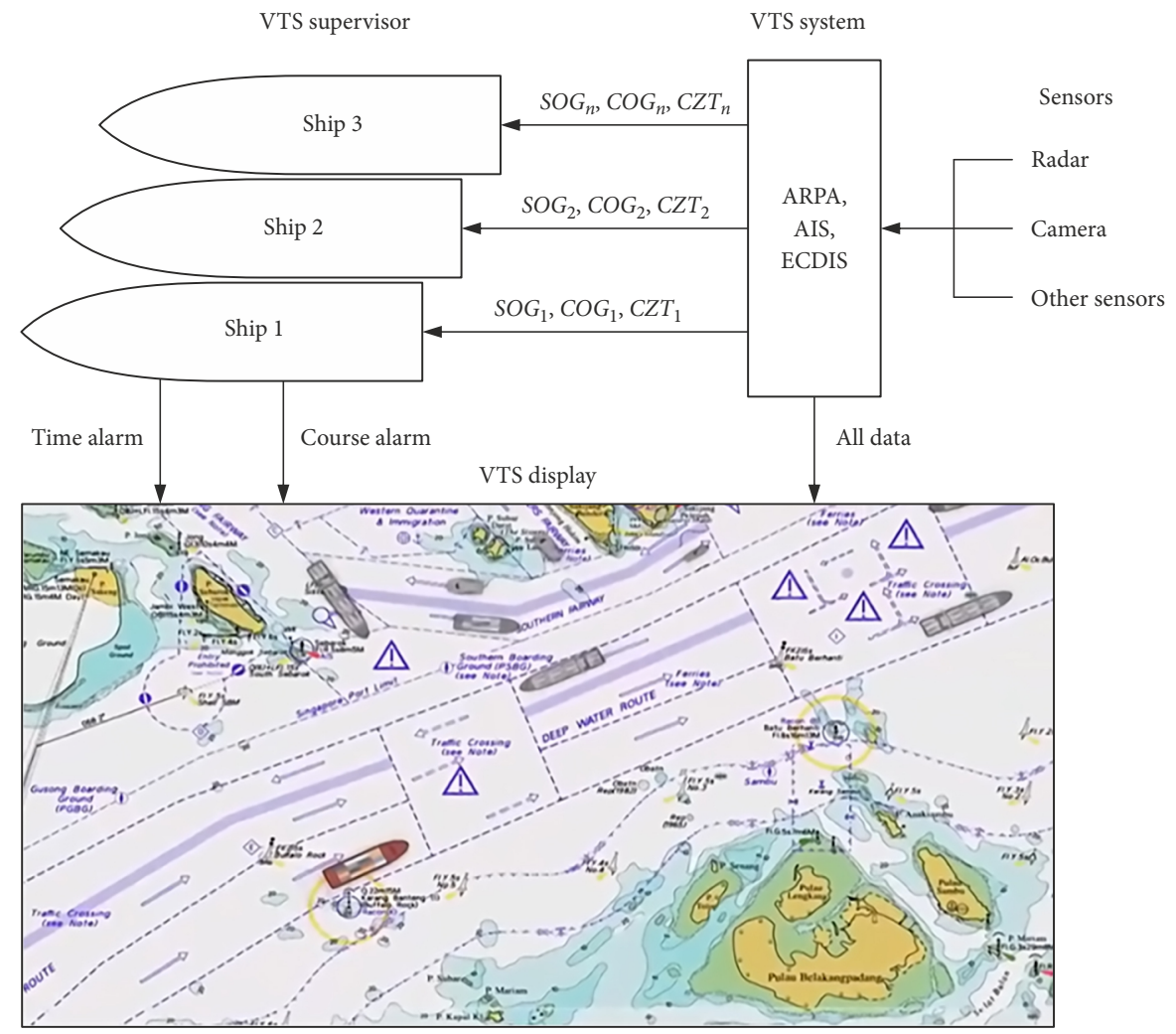

Figure 4. Integration of the VTS supervisor, VTS system and VTS display (SAFETY4SEA 2016)

All these devices collect and process data from different sensors and displays to the VTS display in real time. The task of a VTS supervisor is to automatically monitor every vessel's moving from one zone to another.

The supervisor automatically records data from the VTS system for every ship, such as SOG, COG and CZT, and predicts the time a vessel needs for crossing into the next zone. Then the supervisor compares the predicted CZT of the next zone with the real CZT derived from the VTS system. If there is a deviation, the time alarm for the ship is triggered, and the colour of the vessel on the VTS display is changed to red, which alerts the VTS operator.
In addition, if the VTS supervisor detects changing of the COG that is more than $15^{\circ}$ when ship crosses the zone, the course alarm is triggered. The VTS supervisor, as proposed in this study, should be a software upgrade of the standard VTS system. The supervisor assists the human operator to make the right decisions at the right time, improves his/her concentration and reduces stress in heavy traffic situations.

For modelling and simulation of supervisors, the authors use hybrid Petri nets, the basics of which are presented in the next section. 


\section{Basics of the hybrid Petri net}

The Petri net is a graphical-mathematical tool for describing and analysing discrete event systems, and is extremely helpful in modelling and simulating traffic control systems. The resulting model in the form of Petri net can easily be transformed into control program that can be easily implemented in real time monitoring system.

A general Petri net is defined as the five-tuple (Cassandras, Lafortune 2008):

$$
P N=\left(P, T, A, w, m_{0}\right),
$$

where:

$P=\left\{p_{1}, p_{2}, p_{3}, \ldots, p_{n}\right\}-$ set of places;

$T=\left\{t_{1}, t_{2}, t_{3}, \ldots, t_{n}\right\}-$ set of transitions;

$A \subseteq(P \times T) \cup(T \times P)-$ set of directed arcs;

$w: A \rightarrow\{1,2,3, \ldots\}$ - weight function;

$P \cap T=0$ and $P \cup T \neq 0$;

$m_{0}: P \rightarrow\{0,1,2,3, \ldots\}$ - initial marking.

A place $p$ in Petri net $P N$ can contain one or more tokens. The token is marked as a point within the place (circle). Function $m: P \rightarrow N=\{0,1,2,3, \ldots\}$ assigns the number of tokens $m(p)$ to place $p$. The Petri net marking $\mathbf{m}$ or state is defined by column vector $\mathbf{m}=\left[m\left(p_{1}\right), m\left(p_{2}\right), \ldots, m\left(p_{n}\right)\right]^{T} \in N^{n}$, where $n$ is the number of place in the Petri net. Vector $\mathbf{m}$ shows the number of tokens in place $p_{i}$, which is denoted as $m\left(p_{i}\right)$. The Petri net initial marking $m_{0}$ is a column vector that defines the initial number of tokens in places $\mathbf{m}_{0}=\left[m_{0}\left(p_{1}\right), m_{0}\left(p_{2}\right), \ldots, m_{0}\left(p_{n}\right)\right]^{T} \in N^{n}$. Transition $t_{j}$ $\in T$ (bar) is enabled from marking $m$ if and only if:

$$
\forall p \in \bullet t_{j}: m(p) \geq w\left(p, t_{j}\right) .
$$

Transition $t_{j}$ is enabled if and only if the number of tokens $m(p)$ in all places $p$ having an output arc at the transition $t_{j}$ is greater than the weight factor $w\left(p, t_{j}\right)$ associated with arcs. If the transition $t_{j}$ is enabled, then firing can occur. By firing the transition, the markings of the net changes, the tokens from input places move to the output places. The firing mechanism is formally defined by the state transition function - Equation (3).

The state transition function of the Petri net $f: N^{n} \times T \rightarrow N^{n}$ is defined for transition $t_{j} \in T$ only if the transition is enabled - Equation (2) is satisfied. If the relation (Equation (2)) is satisfied and if function $f\left(m, t_{j}\right)$ is defined, than the transition can fire, and new marking $\mathbf{m}^{\prime}=f\left(m, t_{j}\right)$ is generated:

$$
\begin{aligned}
& m^{\prime}\left(p_{i}\right)=m\left(p_{i}\right)-w\left(p_{i}, t_{j}\right)+w\left(t_{j}, p_{i}\right), \\
& i=1, \ldots, n .
\end{aligned}
$$

Transition from the marking $\mathbf{m}$ to the marking $\mathbf{m}^{\prime}$, which is derived by firing the transition $t_{j}$ can be written $\mathbf{m}\left[t_{j}>\mathbf{m}^{\prime}\right.$.

From Equation (3) it follows that the new state of the Petri net depends on the old state, the way in which the places and transitions are connected, and the weight of the arches that connect them. The state transition function is therefore dependent on the structure of the Petri net. Figure 5 shows the initial marking of the general Petri net.

The initial marking (state) can be described by the initial column vector $m_{0}=\left[\begin{array}{ccccc}1 & 0 & 0 & 0 & 0\end{array}\right]^{T}$. From the initial marking $m_{0}$ the transition $t_{1}$ is enabled because the relation $m_{0}\left(p_{1}\right) \geq w\left(p_{1}, t_{1}\right)$ is satisfied. When the transition $t_{1}$ fires, the token from $p_{1}$ is removed, and new tokens are added to places $p_{2}$ and $p_{3}$. The new marking is $m_{1}=\left[\begin{array}{lllll}0 & 1 & 1 & 0 & 0\end{array}\right]^{T}$. From marking $m_{1}$ the transitions $t_{2}$ and $t_{3}$ can be fired. By firing the transition $t_{2}$ the net changes marking to $m_{2}=\left[\begin{array}{lllll}0 & 0 & 1 & 1 & 0\end{array}\right]^{T} m_{2}$, and by firing the transition $t_{3}$ from marking $m_{1}$ the net changes marking to $m_{2}=\left[\begin{array}{lllll}0 & 1 & 0 & 1 & 1\end{array}\right]^{T}$. The firing process and the change of marking continues in the same way until the Petri net returns to the initial state.

The authors use hybrid Petri net formalism for modelling and simulating the VTS supervisor (David, Alla 2010). In addition to discrete places and transitions, the hybrid Petri net also uses continuous places and transitions. Continuous places and transitions allow modelling of the continuous system that can be described by differential equations. While the tokens in the general Petri net are nonnegative integers, the tokens in the Continuous Petri nets are real numbers. A continuous place is marked as a double circuit, while a continuous transition is marked as an empty bar. Each continuous transition is assigned a "firing speed" that can be a constant or a function. The transition process in the simple Continuous Petri net is shown in Figure 6.

Continuous place $p_{1}$ contains the $m_{1}$ tokens. Transition $T_{1}$ continuously moves the tokens (which are real numbers) from $p_{1}$ to $p_{2}$. The firing speed of the moving token is defined by the function $m_{1}-0.1 \cdot m_{2}$. The number of tokens in place $p_{1}$ decrease according to function

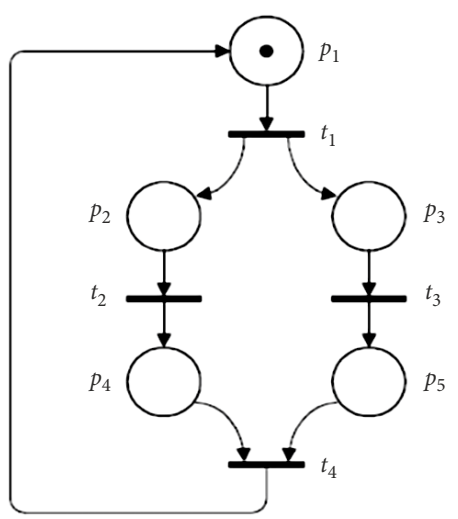

Figure 5. Initial marking of the Petri net $\left(m_{0}\right)$

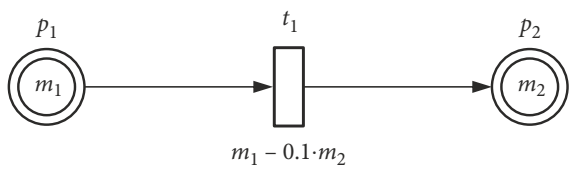

Figure 6. Simple continuous Petri net 
$\frac{d m_{1}}{d t} \cdot m_{1}-0.1 \cdot m_{2}$, and the number of tokens in $p_{2}$ in$d t$
crease according to function $\frac{d m_{2}}{d t} \cdot m_{2}-0.1 \cdot m_{2}$.

There are also three different types of arcs in the hybrid Petri net:

"» ordinary arcs, like in the general Petri net, which are marked by full arrow line;

"» test arcs marked by dotted arrow line;

"» inhibitor arcs marked by full arrow line with a circle at the end.

The difference between ordinary and test arcs is that the test arc does not change tokens in input places. The inhibitor arc prevents firing of transitions even if Equation (2) is satisfied.

\section{Hybrid Petri net VTS supervisor - modelling and simulation: case study of the Dover incident}

In our case, the surveillance area is divided into 5 zones (zones $0 \ldots 4$ ) and corresponds to the zones in the Dover Strait described in Section 2. The dimensions of the zones are $0.5 \times 0.5 \mathrm{~nm}$. The crossing lines between the zones in Figure 7 are marked with $S_{01}, S_{12}, S_{23}, S_{34}$.

Figure 8 presents the hybrid Petri net model of the VTS supervisor, which generates time and course alarms. To show the functionality of the VTS supervisor, the supervisor is tested on three ships in three different routes $R_{1}, R_{2}$ and $R_{3}$, passing through five zones $S_{0} \ldots S_{4}$. Thereby the Petri net model in Figure 8 is generated for each vessel passing through the surveillance area. Figures 9,10 and 11 show the Petri net model of routes $R_{1}, R_{2}$ and $R_{3}$.

The route $1\left(R_{1}\right)$ starts at zone $0\left(S_{0}\right)$. The ship moves from zone $S_{0}$ to zone $S_{1}$, crosses the line $S_{01}$, and enters the surveillance zone 1 . At that particular moment of crossing $S_{01}$, the VTS supervisor records $C O G_{01}=170^{\circ}$, $S O G_{01}=16.8 \mathrm{kn}$ and $C Z T_{01}=0 \mathrm{~min}$. Then, the supervisor calculates the time the ship in route 1 should cross the line $S_{12}$ - the so called estimated crossing time (CZ$T_{\text {estm } 12}$ ). The calculation is based on the assumption that the ship's course and speed will not significantly deviate through zone 1. The formula for the calculation $C Z T_{\text {estm12 }}$ depends on the zone's shape and size. The estimated time $C Z T_{\text {estm12 }}$ is increased by $20 \%$ because there is a possibility of deviation of the course and speed during the navigation in zone 1 and for the zones in Figure 7 it can be calculated using Equation (4):

$$
C Z T_{\text {est } 12}=\frac{36}{S O G_{01} \cdot\left|\cos \left(\left|180^{\circ}-C O G_{12}\right|\right)\right|}[\mathrm{min}] .
$$

The second checkpoint is on line $S_{12}$. When the ship crosses $S_{12}$, the VTS supervisor upgrades the new data $C O G_{12}, S O G_{12}$ and $C Z T_{12}$. Now, the VTS supervisor can decide whether to trigger time or course alarm. The time alarm triggers if the constraint (Equation (5)) is violated and the course alarm triggers if the constraint (Equation (6)) is violated:

$$
\begin{aligned}
& C Z T_{\text {estm12 }}>C Z T_{12} ; \\
& \left|C O G_{01}-C O G_{12}\right|>15^{\circ} .
\end{aligned}
$$

The same calculations are carried out for zones 2 and 3 , until the ship in route 1 crosses line $S_{34}$ and leaves the surveillance zone. In addition, the same algorithm described for route 1 can be applied for routes 2 and 3 . It is important to note that each time the crossing line $S_{01}$ to $S_{34}$ is crossed, the CZT is reset to zero, so that the time of passage through each zone is measured from zero.

The hybrid Petri net model of the VTS supervisor (Figure 8) consists of 22 discrete places, 10 discrete transitions, 4 continuous places and 3 continuous transitions. The VTS supervisor receives data from the VTS system that generates the discrete events and sends data to input places. All input places are shown in Figure 8 as very large circuits. There are 4 input discrete places from Z1-ENTRY to Z4-ENTRY. These places receive tokens when the VTS system detects ship entering a particular zone. There are also 3 continuous places from Z1_SPEED to Z3_SPEED and 4 discrete places from Z1_COURSE to Z4_COURSE. In these places, the VTS system writes the speeds and courses at the time when the ship moves from one zone to another. There are 3 output discrete places from TIME ALARM Z1 to TIME ALARM Z3. These places are marked when the ship does not reach the exit of the zone at the estimated time calculated by the VTS supervisor. In addition, there are 3 output discrete places from Z1-Z2 COURSE to Z3-Z4 COURSE, which calculate the difference between courses at the entrance and exit of the zone. The difference must not be more than $15^{\circ}$. The output places send a signal to the VTS system to trigger an alarm for a particular ship. Marking of discrete places BEFORE ZONE_1, ZONE_2, ZONE_3 and ZONE_4 means that the ship is in the particular zone. Only one of these places can be marked at the same time, because one ship cannot be in more than one zone at the same time. The continuous place DISTANCE continuously calculates the distance that ship makes through the zone. The calculation is based on the SOG and COG using relation (Equation (4)).

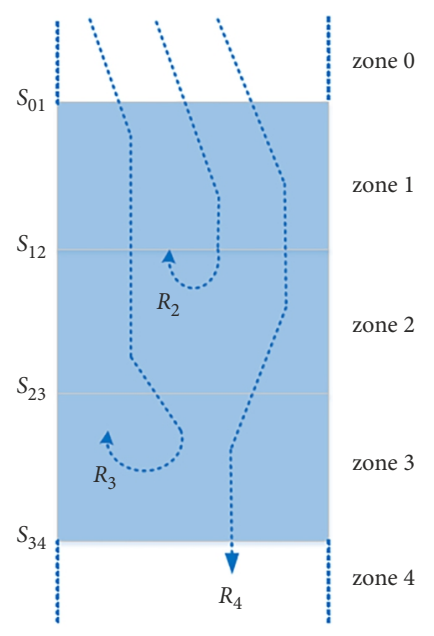

Figure 7. Surveillance area of the VTS supervisor 
In case when the numbers in place DISTANCE reach the value that the ship achieves sailing in the course COG at speed SOG, the place TIME_ALARM for the particular zone is marked.

The hybrid Petri net in Figure 8 shows a ship waiting to enter zone 1 . There are no tokens in input places, so the VTS system has not send any data to the VTS supervisor yet. A marking of the Petri net in Figure 9 shows the state of the VTS supervisor after the ship in route 1 exits zone 3. There is one token in place ZONE_4 (the ship is in zone 4). Data in places from Z1-COURSE to Z4- COURSE and from Z1_SPEED to Z3_SPEED are courses and speeds that the VTS system sent to the VTS supervisor when the ship moved from one zone to another. Places from Z1-Z2 COURSE to Z3-Z4 COURSE show the course difference. The simulation begins when the ship enters zone 1 . The VTS system sends $S O G_{01}=16.8 \mathrm{kn}, C O G_{01}=170^{\circ}$ and $C Z T_{01}=0$ min to the VTS supervisor when the ship moves to zone 1 . Then the VTS supervisor, based on $S O G_{01}$ and $C O G_{01}$ and relation (Equation (4)), estimates the time that the ship needs to reach zone 2 . The maximally allowable estimated time for zone1 is $C Z T_{\text {estm } 12}=2.17 \mathrm{~min}$. The VTS supervisor then waits for new data from the VTS system. When the ship entered zone 2, the VTS sent a new information $S O G_{12}=15.6 \mathrm{kn}, C O G_{12}=180^{\circ}$ and $C Z T_{12}=2.1 \mathrm{~min}$. Then, the VTS supervisor detects violation of the constraints (Equations (5) and (6)). If the ship reaches zone 2 at $C Z T_{12}<2.18 \mathrm{~min}$ (the VTS system sends the token to place Z2_ENTRY before 2.18 min elapsed), the travel time for the ship is normal, the token remains in place TIME NORMAL Z1. If the ship reaches zone 2 at $C Z T_{12} \geq 2.18 \mathrm{~min}$, the token moves to TIME ALARM $\mathrm{Z1}$, and the colour of the ship changes at VTS display indicating the abnormality. In addition, the VTS supervisor calculates the difference of $C O G_{01}-C O G_{12}$ and store the results in place Z1-Z2 COURSE. Furthermore, if the relation (Equation (6)) is violated, the course alarm occurs. The same algorithm repeats while the ship sails through zones 2 and 3, and finishes when the ship crosses line $S_{34}$.

The supervisor in Figure 9 did not generate time and course alarms. Time alarms for all three zones were not triggered (there were no tokens in places from TIME ALARM Z1 to TIME ALARM Z3), because the VTS system sent the token to input places from Z1-ENTRY to Z4-ENTRY before the estimated time for a ship passing a particular zone elapsed. In addition, there were no course alarms, because the course difference at the entrance of the zones (places from Z1-Z2 COURSE to Z3-Z4 COURSE) did not exceed $15^{\circ}$.

A marking of the Petri net in Figure 10 shows the state of the VTS supervisor when the ship in route 2 stuck in zone 2 . The ship in route 2 moved from zone 1 to zone 2 within estimated time for zone 1 , so the time alarm for zone 1 did not trigger (place TIME_ ALARM Z1 is empty). The course difference $\left|C O G_{01}-C O G_{12}\right|=10^{\circ}$, so the course difference is allowable. At the entrance into zone 2 the $S O G_{12}=15.6 \mathrm{kn}$. The ship in zone 2 performed an unallowable turn back, and stuck in zone 2, not being able to reach zone 3 in the estimated time for zone $2\left(C Z T_{\text {estm } 23}=\right.$ $2.31 \mathrm{~min})$. The VTS supervisor triggered the time alarm for zone 2 after the time $C Z T_{\text {estm } 23}$ elapsed (place TIME ALARM Z2 is marked). This alarm warned the VTS operator that something unpredictable happened with the ship by changing the colour of the ship at VTS display.

A marking of the Petri net in Figure 11 shows the state of the VTS supervisor for the ship in route 3 . The ship in route 3 started to turn back in the middle of zone 2 . The ship moved from zone 2 to zone 3 within estimated time for zone 2, but the course difference $\left|C O G_{12}-C O G_{23}\right|=$ $20^{\circ}$, and the relation (Equation (6)) was violated. The course alarm for the ship in route 3 was triggered.

The authors made a hybrid Petri net model of the VTS supervisor in Figure 8 by using simulation software Visual Object Net ++ (Parasoft 2019). The same calculation is carried out for zones 2 and 3 , until the ship in route 1 crosses line $S_{34}$ and leaves surveillance area. The same algorithm, as described for route 1 , can also be applied for routes 2 and 3, which are shown in Figure 7. This Petri net model is generated for each vessel passing through the surveillance area.

\section{Results and discussion}

The VTS is the service developed and implemented to improve the safety and efficiency of vessel traffic and to protect the marine environment. The service is designed to have the capability to interact with the traffic and respond to the traffic situation developing in a specific VTS area. The VTS in the Dover Strait is developed through the INS, TOS and NAS. The aim of this study is to additionally enhance and upgrade all of these parts, in particular the INS (the position, identity or intentions of other vessels in the VTS area and any other information that could affect a vessel's safe transit) and the NAS (course to make good to a given waypoint, speed and crossing time zone).

Improvement of the existing system is achieved through the implementation of the supervisor related to the VTS with the support of hybrid Petri net, as defined in Figures 8, 9 and 10. The authors developed a hybrid Petri net model of the VTS supervisor, and made simulations of three scenarios based on the case study of the Dover incident.

Table 1 shows the measured data for every route. The VTS system sends data to the VTS supervisor at times when ships cross the surveillance zones. The basic measurement data are COG, SOG and CZT. Using nautical simulator, the time of crossing $S_{12}, S_{23}$ and $S_{34}$ are recorded, and the parameters COG, SOG and CZT are shown in Table 1. The CZT time for $S_{01}$ are zero for all routes. The abbreviation $\mathrm{n} / \mathrm{a}$ in the table means that the data are not available. For example, SOG for route 2 in $S_{23}$ is not available because the ship is circling in zone 2 . 


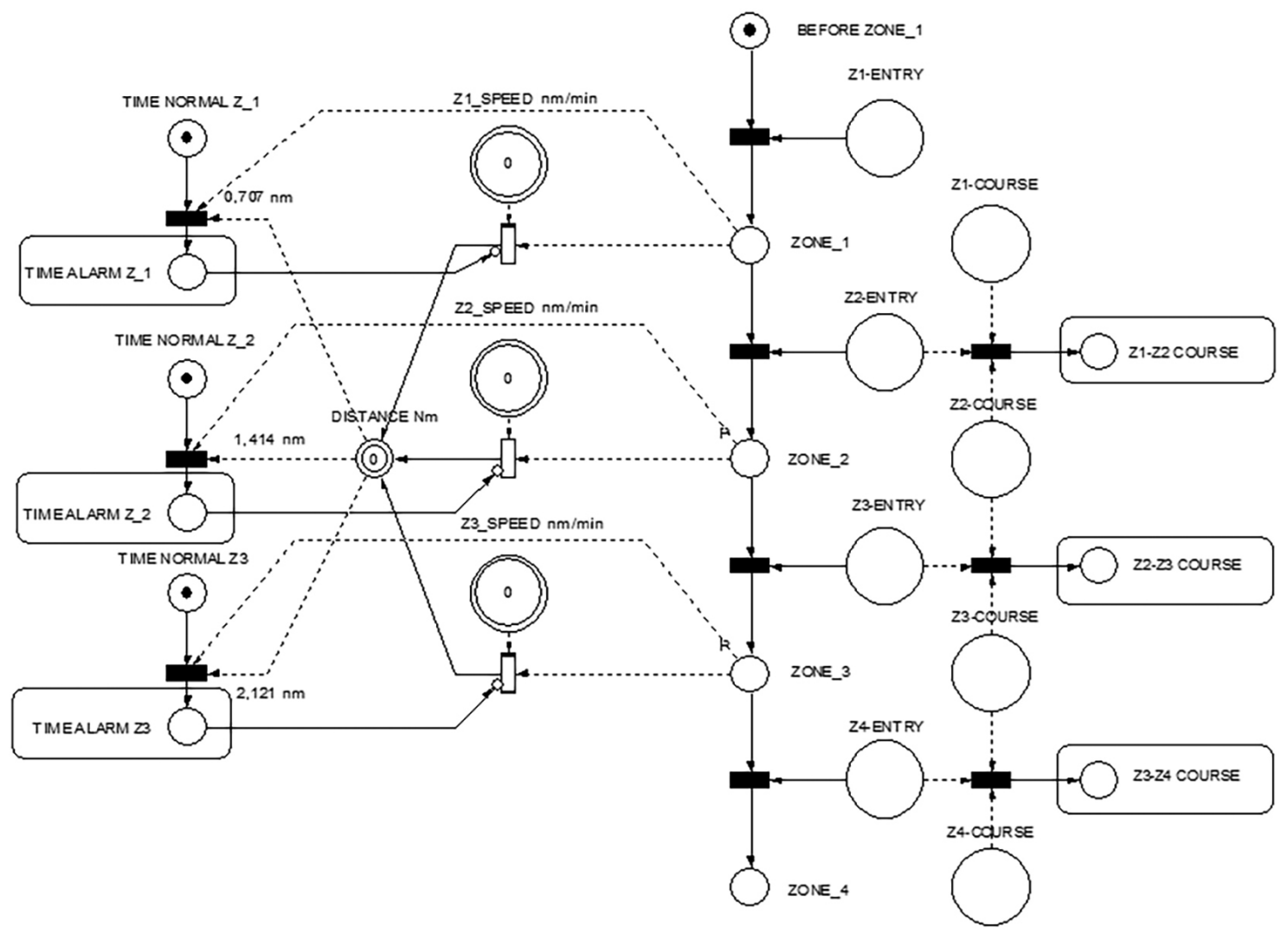

Figure 8. Hybrid Petri net model of the VTS supervisor

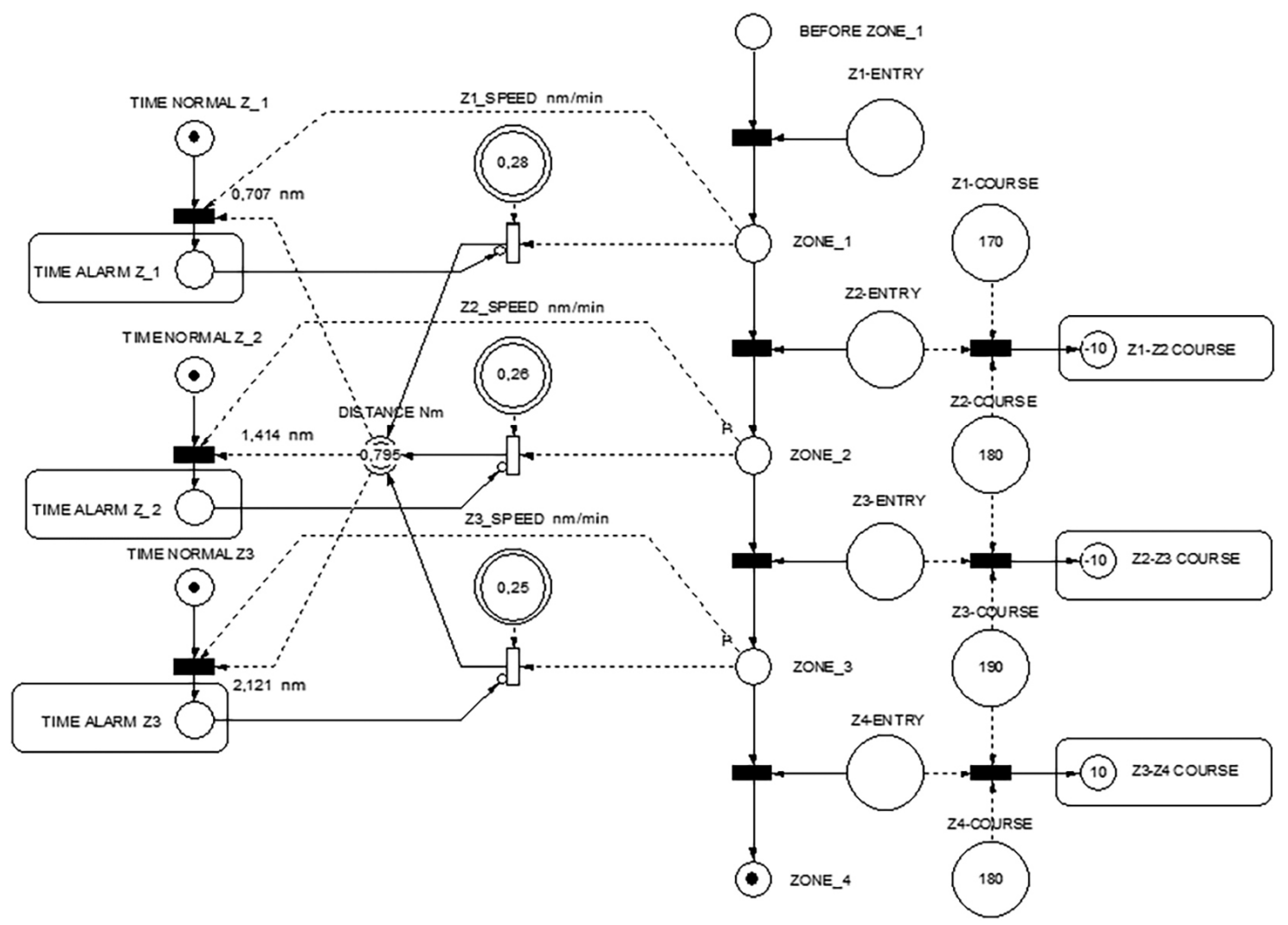

Figure 9. Hybrid Petri net model of the VTS supervisor - ship on route 1 


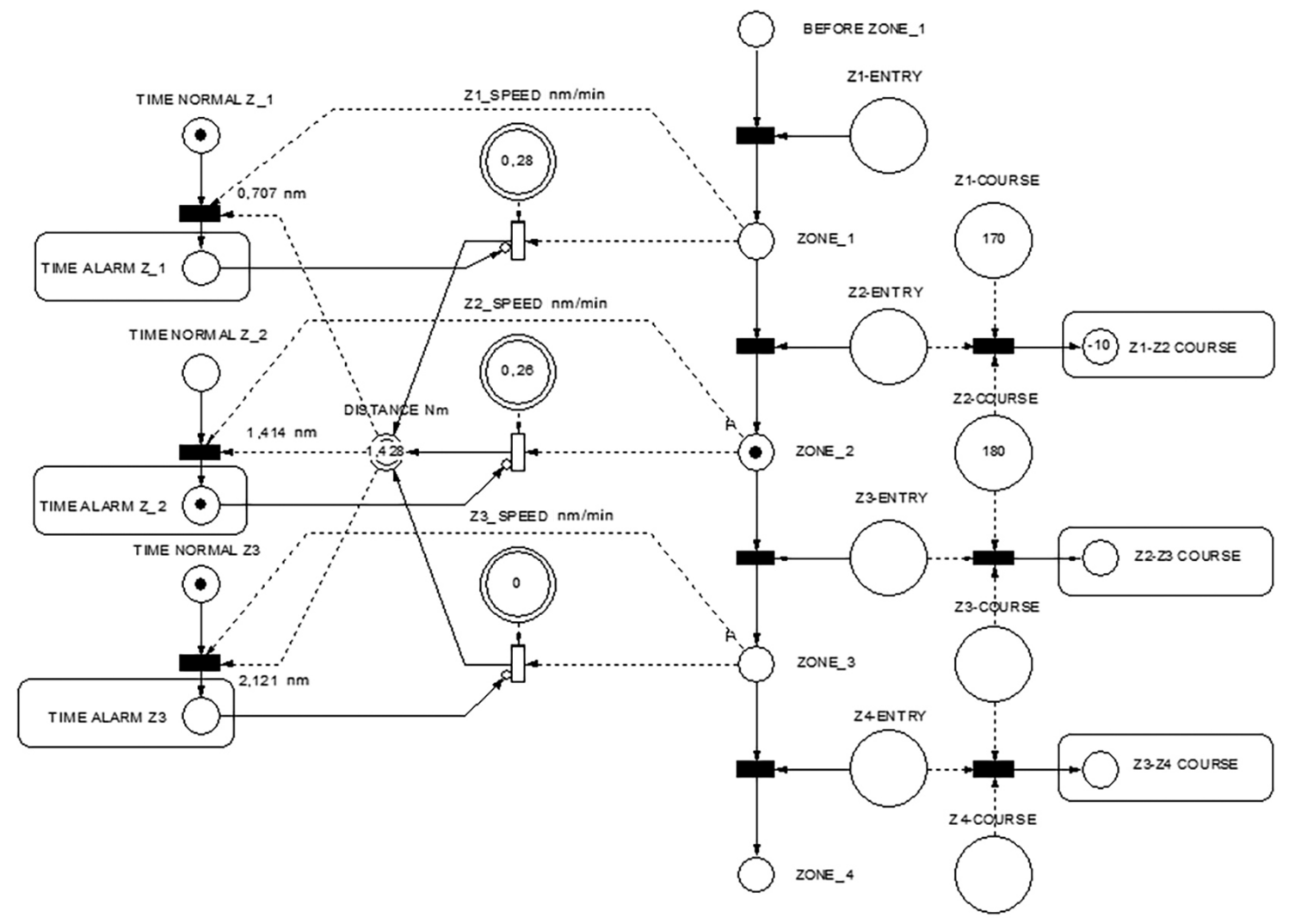

Figure 10. Hybrid Petri net model of the VTS supervisor - ship on route 2

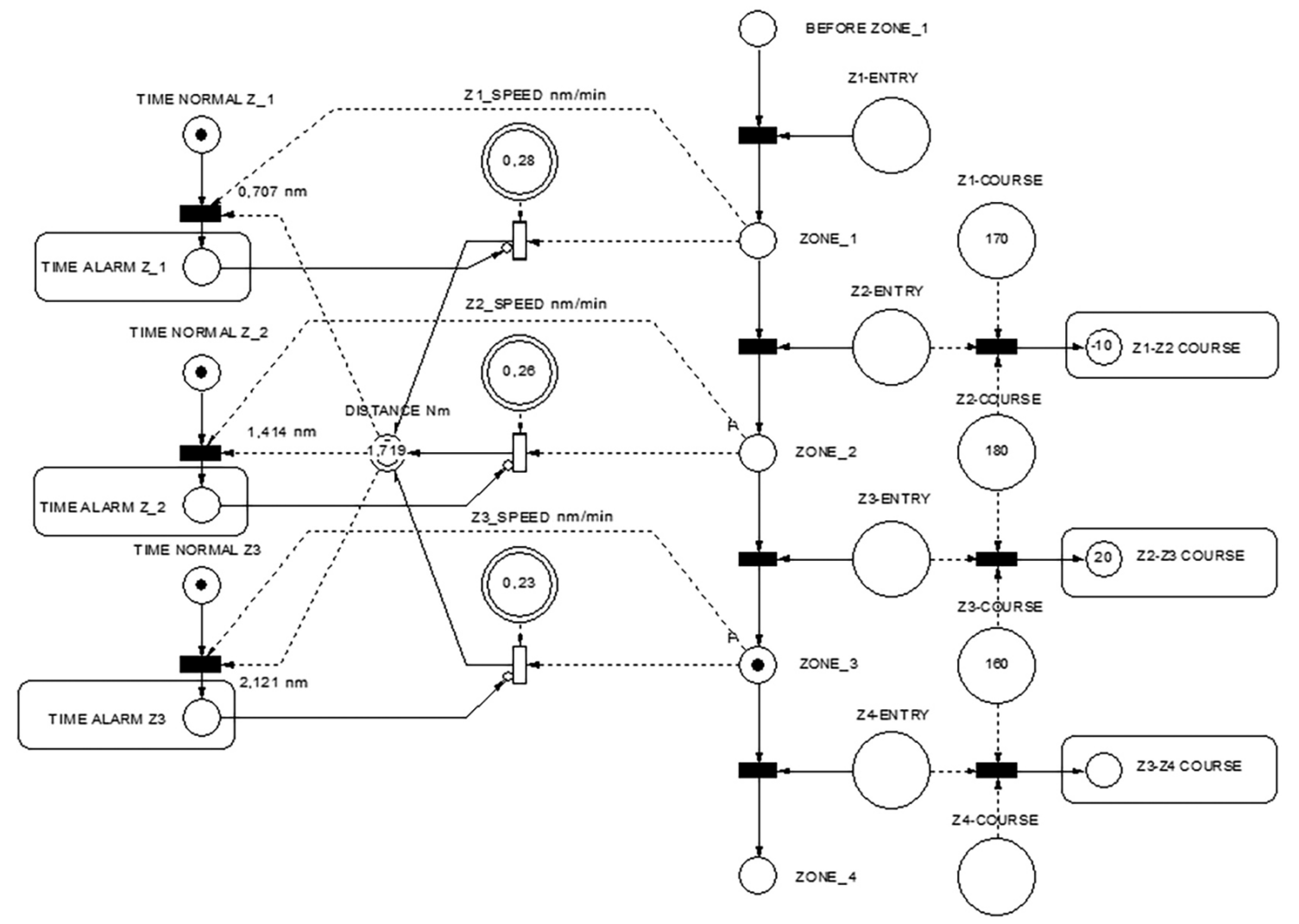

Figure 11. Hybrid Petri net model of the VTS supervisor - ship on route 3 
Table 1. Data from VTS supervisor

\begin{tabular}{|c|c|c|c|c|c|c|c|c|c|}
\hline \multicolumn{10}{|c|}{ VTS supervisor input data } \\
\hline & \multicolumn{3}{|c|}{$\operatorname{COG}\left[^{\circ}\right]$} & \multicolumn{3}{|c|}{ SOG $[\mathrm{kn}]$} & \multicolumn{3}{|c|}{$\mathrm{CZT}[\mathrm{min}]$} \\
\hline Line Route & $R_{1}$ & $R_{2}$ & $R_{3}$ & $R_{1}$ & $R_{2}$ & $R_{3}$ & $R_{1}$ & $R_{2}$ & $R_{3}$ \\
\hline$S_{01}$ & 170 & 170 & 170 & 16.8 & 16.8 & 16.8 & 0 & 0 & 0 \\
\hline$S_{12}$ & 180 & 180 & 180 & 15.6 & 15.6 & 15.6 & 2.1 & 1.9 & 1.8 \\
\hline$S_{23}$ & 190 & $\mathrm{n} / \mathrm{a}$ & 160 & 13.8 & $\mathrm{n} / \mathrm{a}$ & 12.6 & 2.3 & $\mathrm{n} / \mathrm{a}$ & 1.91 \\
\hline$S_{34}$ & 180 & $\mathrm{n} / \mathrm{a}$ & $\mathrm{n} / \mathrm{a}$ & 14.4 & $\mathrm{n} / \mathrm{a}$ & $\mathrm{n} / \mathrm{a}$ & 2.6 & $\mathrm{n} / \mathrm{a}$ & $\mathrm{n} / \mathrm{a}$ \\
\hline
\end{tabular}

Table 2. Calculated data from the supervisor

\begin{tabular}{|c|c|c|c|c|c|c|c|c|c|}
\hline \multicolumn{10}{|c|}{ VTS supervisor calculation } \\
\hline & \multicolumn{3}{|c|}{ Absolute course deviation } & \multicolumn{3}{|c|}{ Estimated distance [nm] } & \multicolumn{3}{|c|}{ Estimated time $\mathrm{CZT}_{e s t m}[\mathrm{~min}]$} \\
\hline Line Route & $R_{1}$ & $R_{2}$ & $R_{3}$ & $R_{1}$ & $R_{2}$ & $R_{3}$ & $R_{1}$ & $R_{2}$ & $R_{3}$ \\
\hline$S_{12}$ & 10 & 10 & 10 & 0.51 & 0.51 & 0.51 & 2.18 & 2.18 & 2.18 \\
\hline$S_{23}$ & 10 & $\mathrm{n} / \mathrm{a}$ & 20 & 0.50 & 0.50 & 0.50 & 2.31 & 2.31 & 2.31 \\
\hline$S_{34}$ & 10 & $\mathrm{n} / \mathrm{a}$ & $\mathrm{n} / \mathrm{a}$ & 0.51 & $\mathrm{n} / \mathrm{a}$ & 0.53 & 2.65 & $\mathrm{n} / \mathrm{a}$ & 3.04 \\
\hline & & & \multicolumn{4}{|c|}{ Course alarm } & \multicolumn{3}{|c|}{ Time alarm } \\
\hline & & & Line Route & $R_{1}$ & $R_{2}$ & $R_{3}$ & $R_{1}$ & $R_{2}$ & $R_{3}$ \\
\hline & & & $S_{12}$ & no & no & no & no & no & no \\
\hline & & & $S_{23}$ & no & no & yes & no & yes & no \\
\hline & & & $S_{34}$ & no & no & $\mathrm{n} / \mathrm{a}$ & no & no & yes \\
\hline
\end{tabular}

Table 2 shows output data calculated by the VTS supervisor. Table shows that the VTS supervisor performs three calculations for each route:

"»" absolute course deviation between crossing lines;

"» estimated distance between crossing lines based on previous COG;

"» estimated time to next crossing line - Equation (4).

Based on this data, the VTS supervisor uses Equations (5) and (6) to decide whether to activate a course or time alarm.

It is observed from Table 2 that the ship in route 1 does not violate conditions (Equations (5) and (6)) and that the supervisor did not activate any alarms in crossing lines $S_{12}, S_{23}, S_{34}$. On the other hand, the ship on route 2 violated condition (Equation (5)) and therefore the alarm in crossing line $S_{23}$ was activated, which warns the operator to analyse the ship's delay in $S_{23}$. For the ship on route 3 , the alarm in crossing line $S_{23}$ is triggered due to violation of conditions (Equation (5)) and the course alarm in crossing line $S_{34}$ due to violation of catch (Equation (6)) is activated.

The scenario 1 contains a normal passing through the sector. The scenario 2 involves turning back inside the sector, while the third scenario is the start of turnaround in zone 2 and continuation in zone 3 . In case of scenario 2, the VTS supervisor activated the time alarm because the ship did not appear at the entrance of the next sector in the estimated time. In case of scenario 3, the VTS supervi- sor activated the course alarm and time alarm, because the ship entered the next zone with a course that significantly deviated from the course that was held in the previous zone and did not appear at the entrance of the next sector in the estimated time.

The reaction time of the VTS operator to the irregular ship behaviour in the Dover Strait incident was about 5 min. Simulations shows that if the VTS system had the proposed VTS supervisor, the VTS operator would be warned of a danger in approximately $2.5 \mathrm{~min}$ at the most.

\section{Conclusions}

This paper proposes the implementation of an automated supervisor to the VTS system. The main task of the proposed VTS supervisor is to automatically alert the VTS operator of the unallowable behaviour of ships in the surveillance area. The suggested VTS supervisory system should ensure the compliance with the restrictions regarding the danger (observed as incidents and accidents that already happened) such as passing in close quarter situations. The VTS supervisor can be applied for vessels passing through narrow straits, channels, entrances to busy anchorages and to congested ports.

The authors propose a division of the surveillance area in small sectors (zones). The main task of the supervisor is to collect data (course, speed, time) from the VTS system at the particular time instants when a ship moves 
from one sector to another. Relying on this data, the VTS supervisor estimates the time that the ship needs to move to the next sector. If a particular ship violates the time and course criteria (in defined constraints), the VTS supervisor triggers the time or course alarms by changing the ship designation to red colour. So far, various research studies and analyses presented in a number of scientific papers have not resulted in the development of an automatic supervising system that triggers two types of alarm and gives an immediate warning to the VTS supervisor who is responsible to alert the ship immediately once the alarm is triggered.

Therefore, the main contribution of this study to the quality of the automated traffic monitoring is the suggested with introduction of the automatic supervisor that alerts the VTS human operator to certain irregularities of ship traffic in real time. The contribution is a new algorithm module that, for each ship, records the speed and course and estimates the time of exit from the observed sector and entry into the next sector. The algorithm detects deviations between real and estimated time of passage through the sector as well as the entry of the ship into the wrong sector. However, the proposed algorithm does not monitor the ship's course and speed continuously within the sector. In this way, the amount of data that the supervisor processes is small. The algorithm for estimating the time of exit from the sector is simple, which ensures high speed of calculation in real time, and the proposed algorithm can be easily integrated into the software of the existing VTS systems just by adding a software module. Such modification of VTS supervisor is reliable and relatively inexpensive and no special preparation activities are required for its application. Such software module could be developed by using the algorithm based on the Petri net model described in this paper. The suggested methodology is suitable for other sea straits worldwide, particularly for narrow straits such as the Gibraltar Strait, the Singapore Strait and other narrow channels.

\section{Author contributions}

Rino Bošnjak was responsible for the main aim of this study research and wrote the first draft of the paper.

Danko Kezić and Goran Belamarić were responsible for the designing and developing model by using Petri nets.

Srećko Krile was responsible for data interpretation.

\section{Funding}

There is no funding.

\section{Disclosure statement}

There is no competing financial, professional or personal interest from other parties.

\section{References}

Aydogdu, Y.; Yurtoren, C.; Park, J.; Park, Y. 2012. A study on local traffic management to improve marine traffic safety in the Istanbul Strait, Journal of Navigation 65(1): 99-112. https://doi.org/10.1017/S0373463311000555

Bielić, T.; Hasanspahić, N.; Čulin, J. 2017. Preventing marine accidents caused by technology-induced human error, Scientific Journal of Maritime Research 31: 33-37.

Bošnjak, R.; Kezić, D.; Vidan, P.; Kavran, Z. 2020. Collision prevention in Singapore Strait by using timed Petri net, Transport 35(3): 273-282. https://doi.org/10.3846/transport.2019.11623

Cassandras, C. G.; Lafortune, S. 2008. Introduction to Discrete Event Systems. Springer. 772 p. https://doi.org/10.1007/978-0-387-68612-7

Chong, J. C. 2018. Impact of Maritime Autonomous Surface Ships (MASS) on VTS Operations. Dissertation. Sweden: World Maritime University, Malmö, Sweden 72 p. Available from Internet: https://commons.wmu.se/all_dissertations/647

Cockcroft, A. 2004. The Dover Strait traffic separation scheme, Journal of Navigation 57(1): 161-165. https://doi.org/10.1017/S0373463303212613

David, R.; Alla, H. 2010. Discrete, Continuous, and Hybrid Petri Nets. Springer. 550 p. https://doi.org/10.1007/978-3-642-10669-9

Emden, R. 1983. The channel navigation information service, Journal of Navigation 36(2): 195-210. https://doi.org/10.1017/S0373463300024917

Filipowicz, W. 2004. Vessel traffic control problems, Journal of Navigation 57(1): 15-24.

https://doi.org/10.1017/S0373463303002480

Kim, J.-S. 2013. A basic study on the VTS operator's minimum safe distance, Journal of the Korean Society of Marine Environment \& Safety 19(5): 476-482. (in Korean). https://doi.org/10.7837/kosomes.2013.19.5.476

Lee, H.-K.; Chang, S.-R.; Jeong, G.-N.; Park, Y.-S. 2010. A proposal on the marine traffic supporting system in VTS area, Journal of Navigation and Port Research 34(9): 693-698. https://doi.org/10.5394/KINPR.2010.34.9.693

Mazzarella, F; Arguedas, V. F.; Vespe, M. 2015. Knowledge-based vessel position prediction using historical AIS data, in 2015 Sensor Data Fusion: Trends, Solutions, Applications (SDF), 6-8 October 2015, Bonn, Germany, 1-6. https://doi.org/10.1109/SDF.2015.7347707

MCGA. 2014. Dover Strait Crossings: Channel Navigation Information Service. Maritime and Coastguard Agency (MCGA), Southampton, UK. Available from Internet: https://www.gov. uk/government/publications/dover-strait-crossings-channelnavigation-information-service/dover-strait-crossings-channel-navigation-information-service-cnis

Neill, H. 1990. The channel navigation information service for the Dover Strait, Journal of Navigation 43(3): 331-342. https://doi.org/10.1017/S0373463300013977

Parasoft. 2019. Visual Objects 2.7 Net Version. Available from Internet: https://de.parasoft.com

Patmanidis, S.; Voulgaris, I.; Sarri, E.; Papavassilopoulos G.; Papavasileiou, G. 2016. Maritime surveillance, vessel route estimation and alerts using AIS data, in 2016 24th Mediterranean Conference on Control and Automation (MED), 21-24 June 2016, Athens, Greece, 809-813. https://doi.org/10.1109/MED.2016.7535966 
Porathe, T.; Prison, J.; Man, Y. 2014. Situation awareness in remote control centres for unmanned ships, in Human Factors in Ship Design \& Operation, 26-27 February 2014, London, UK, 1-9.

Praetorius, G. 2014. Vessel Traffic Service (VTS): a Maritime Information Service or Traffic Control System? Understanding Everyday Performance and Resilience in a Socio-Technical System Under Change. Thesis for the Degree of Doctor of Philosophy. Chalmers University of Technology, Gothenburg, Sweden. 73 p.

SAFETY4SEA. 2016. New Programme for Safe Navigation Launched. Available from Internet:

https://safety4sea.com/new-programme-for-safe-navigationlaunched

Squire, D. 2003. The hazards of navigating the Dover Strait (Pasde-Calais) traffic separation scheme, Journal of Navigation 56(2): 195-210. https://doi.org/10.1017/S0373463303002182

Weng, J.; Meng, Q.; Qu, X. 2012. Vessel collision frequency estimation in the Singapore Strait, Journal of Navigation 65(2): 207-221. https://doi.org/10.1017/S0373463311000683 